\title{
TECHNOLOGICAL DEVELOPMENT OF A YARN GRIP SYSTEM FOR HIGH-SPEED TENSILE TESTING OF HIGH-PERFORMANCE FIBERS
}

\author{
Reimar Unger, Philipp Schegner, Andreas Nocke, Chokri Cherif \\ Technische Universität Dresden, Faculty of Mechanical Science and Engineering, \\ Institute of Textile Machinery and High Performance Material Technology (ITM), 01062 Dresden, Germany \\ E-mail: reimar.unger@tu-dresden.de
}

\begin{abstract}
:
Particularly in terms of carbon fiber (CF) rovings and further high performance fibers, it is a highly demanding task to clamp technical yarns with low elongations at break during high-speed tensile tests due to their sensitivity to shear stress. For fibers to be tested, a low elongation at break results in short testing times and requires high acceleration. In this paper, four different yarn grips that can be applied with various test machines will be introduced and compared to a wedge screw grip. By using most sensitive CF rovings, advantages and disadvantages of these gripping devices will be qualitatively evaluated by means of testing machines with test speeds of up to $20 \mathrm{~m} / \mathrm{s}$ and strain rates of up to $200 \mathrm{~s}^{-1}$, respectively. Hence, the reproducibility and precision of test results were considerably enhanced by optimizing the geometry and mass of yarn grips. Moreover, theoretical approaches and calculations for the design of yarn grips suitable for test speeds of up to $100 \mathrm{~m} / \mathrm{s}$ will be presented.
\end{abstract}

\section{Keywords:}

carbon, high performance fiber, strain rate, tensile testing

\section{Introduction}

Profound knowledge of material characteristics is a crucial factor in any type of engineering construction. In addition to static behavior, knowledge of dynamic material behavior is becoming increasingly important for the design and simulation of innovative construction designs in the fields of automotive and rail [1], aerospace [2], and civil engineering [3, 4]. The investigations involved in this process differ between metal materials and fiber-reinforced plastics (FRPs). The unique features of FRPs consist of their anisotropy and distribution of pressure- and tensile load-absorbing components. Tensile forces are mainly governed by fiber reinforcements; therefore, tensile testing results are an essential aspect for the determination of mechanical material properties. For fibers made from carbon (CF), glass (GF), and aramid (AR), which are extensively used for technical textiles today [5], regulations for the standardized determination of tensile properties in the quasi-static range are provided by ISO 2062:2009. In contrast, comparable standardized regulations do not yet exist for testing in the dynamic range. However, this research area is gaining importance in order to make lightweight engineering more efficient. In-depth knowledge of dynamic material behavior should enable more efficient use of materials while simultaneously preserving the structural integrity of a component under dynamic load. Although there are numerous research activities focused on novel testing methods for textiles as well as for requirement-adapted reinforcing structures in the field of FRP [6-15], current insight into fiber properties is mainly based on research results according to Wang et al. [16, 17].

Their investigations evaluated material characteristics through a combination of quasi-static and dynamic tensile tests. Due to the operating principle of the employed test devices, there is a lack of measurement values in the strain rate region of $0.01-500 \mathrm{~s}^{-1}$.

Dynamic tensile testing covers the very broad range of nonquasi-static tensile tests. The relation with specific dynamic material behavior is established by means of strain rate $\varepsilon$ instead of speed $v$. Moreover, the strain rate $\dot{\varepsilon}$ is a time derivation of strain $\varepsilon$ generated during the testing procedure (Equation 1).

$$
\begin{aligned}
& \varepsilon=\frac{\Delta l}{l_{0}} \\
& \dot{\varepsilon}=\frac{d \frac{\Delta l}{l_{0}}}{d t}=\frac{1}{l_{0}} \cdot \frac{d \Delta l}{d t}=\frac{v}{l_{0}}
\end{aligned}
$$

The strain rate is therefore the quotient of the applied testing speed and the initial length $l_{0}$ of the specimen (Equation 2). In the quasi-static range, strain rates of up to $0.01 \mathrm{~s}^{-1}$ can be achieved at deformation speeds of $500 \pm 10 \mathrm{~mm} / \mathrm{min}$ or $250 \pm 5 \mathrm{~mm} / \mathrm{min}$. However, in this paper, specimen grips suitable for testing at strain rates of up to $10^{3} \mathrm{~s}^{-1}$ will be introduced.

An overview illustrating testing scenarios dependent on the strain rate is provided in Figure 1. In terms of quasi-static and long-term tests, the mass and inertia of clamping devices are negligible factors. In contrast, their influence must be taken into consideration for the construction process in the case of dynamic tests. 


\section{Strain-rate regions}

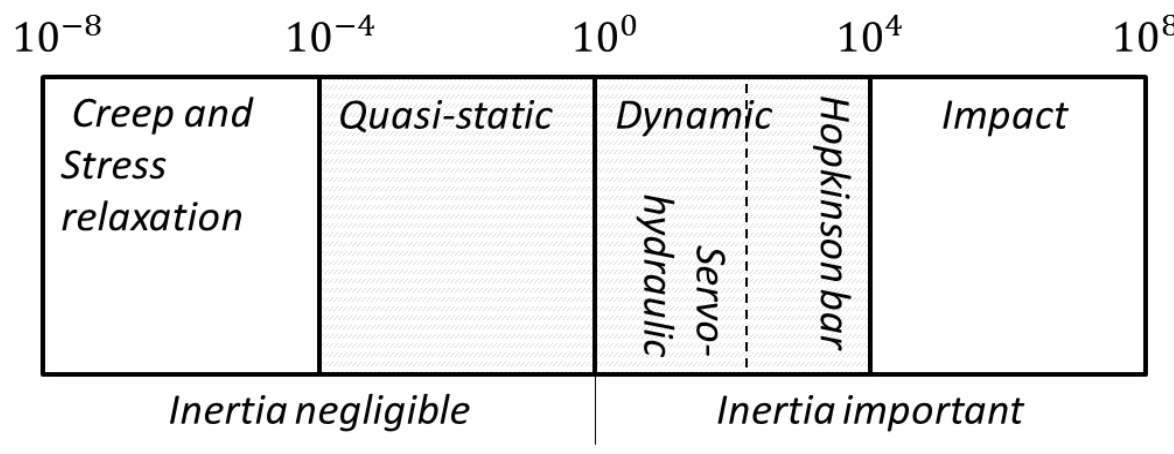

Figure 1. Categorization of strain rate regions for material testing according to the study by Field et al. [18]

$$
t_{\mathrm{P} \text { min }}=\frac{\varepsilon_{B} \cdot l_{0}}{v_{\mathrm{P}}}=\frac{\varepsilon_{B}}{\dot{\varepsilon}_{B}}
$$

The desired strain rates affect testing duration, which can be estimated based on two assumptions. First, immediately following test initialization, the effective speed of the specimen reaches the testing speed $v_{\mathrm{P}}$, and the specimen is under strain until it fractures.

Second, the specimen accelerates approximately linearly during the entire testing period until achieving the test speed immediately prior to fracture.

$$
\begin{aligned}
& v=a \cdot t \text { with } v_{\mathrm{P}}=a \cdot t_{\mathrm{P} \max } \text { and } a=\text { const. } \\
& t_{\mathrm{P} \max }=\frac{\varepsilon_{B} \cdot l_{0}}{0,5 \cdot v_{\mathrm{P}}}=2 \cdot \frac{\varepsilon_{B}}{\dot{\varepsilon}_{B}}
\end{aligned}
$$

The maximal testing duration $t_{\mathrm{P} \max }$ can be determined based on the low elongation at break of $0.5 \%-5 \%$ of the materials to be tested (CF, GF, and $A R$ ) and the selected strain rates of up to $10^{3} \mathrm{~s}^{-1}$. This relationship is illustrated in Figure 2. Equations (3) and (5) also reveal that test duration does not depend on specimen length and test speed, provided there are a defined elongation at break and strain rates. The acceleration process up to reaching the testing speed is the only aspect affecting test duration.

To achieve these high speeds, there are various test procedures suitable for different testing devices and test stands, whereby only some of these cover the entire speed spectrum. They can mainly be differentiated by the type of kinetic energy for the acceleration and strain subjected to the specimen until rupture.

Spindle-driven machines, such as the Zwick Z100, are used for the quasi-static speed range. These testing devices are characterized by robust mechanics in addition to precisely adjustable speeds. As the Zwick Z100 reaches its maximum speed at $600 \mathrm{~mm} / \mathrm{min}$, it is not suitable for testing in the dynamic range and was therefore not considered further. A drop tower is typically a self-made construction with the kinetic energy caused by dropping weight being pressed onto one end of the specimen. Due to construction design, higher speeds (above $10 \mathrm{~m} / \mathrm{s}$ ) can only be achieved with laborious measures. The lower limit is $1 \mathrm{~m} / \mathrm{s}$ and the corresponding drop height is $0.05 \mathrm{~m}$, resulting from a relation between impact energy and constructive implementation of the release. Currently, servohydraulic testing machines achieve speeds from $0.001 \mathrm{~m} / \mathrm{s}$ [19] up to $25 \mathrm{~m} / \mathrm{s}$, therefore, nearly covering the entire quasi-static

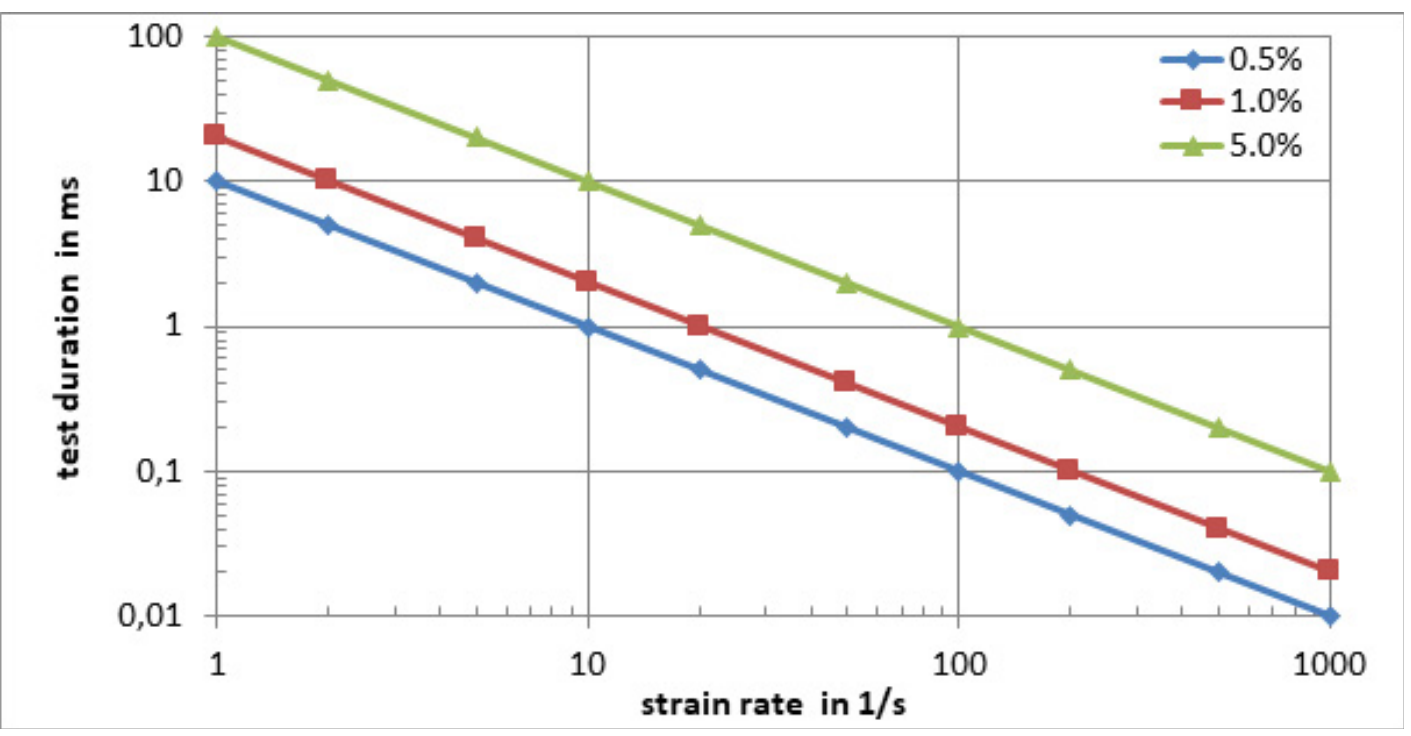

Figure 2. Maximal test duration until rupture at given test speed of specimens with elongations at break of $0.5 \%, 1 \%$, and $5 \%$ and linear acceleration during the entire test period 
and dynamic ranges. Based on calculations, the servo-hydraulic method reaches strain rates of up to $500 \mathrm{~s}^{-1}$ for a maximum specimen length of $50 \mathrm{~mm}$. Test stands according to the SplitHopkinson bar are used for strain rates exceeding $500 \mathrm{~s}^{-1}$ as they are suitable for strain rates of $1,000 \mathrm{~s}^{-1}$ and above. In the case of the Split-Hopkinson tension bar, the specimen is adhesively bonded to two long metal bars and slightly pretensioned. For testing purposes, a striker bar is accelerated so that it hits the input bar, which transfers the major part of the impulse to the specimen while reflecting a minor part of the impulse. Within the specimen, the impulse is transferred in a similar way, partially transmitted, and reflected on each end of the specimen. An output bar is placed at the opposite end of the specimen that conducts the impulse analogously to the input bar. When the specimen fails, the impulse transmission through the specimen is interrupted. The longitudinal strain waves generated through impulses are measured by applied strain gauges. Acting forces are determined by means of the strain-time curves as well as given material parameters and geometries of input and output bars. This test stand was not available to the research project presented in this paper; hence, it was not considered further. Nevertheless, it could be of great interest to future research projects. Although there are conceptual differences, several fundamental common features can be derived for dynamic testing. For example, the specimen is in a state of rest during the accumulation of kinetic energy and is not connected to the energy supply system. One of the two specimen ends (the fixed one) is completely fixed during the entire testing procedure. In contrast, kinetic energy is coupled into the other specimen end that is to be accelerated. Typically, there is a measuring unit mounted onto the fixed end of the specimen to record acting force.

Thus, the introduction of energy required for the acceleration of the specimen poses a major challenge in the experimental setup. It is realized by a mechanical impact by which the kinetic energy, i.e. the moving mass, meets the free specimen end at rest, i.e. the specimen grip. In conclusion, the specimen gripping device must meet two essential requirements to enable successful testing and conclusive results; it must precisely arrange the specimen and accelerate the specimen end.

Most testing machines have not been designed for the investigation of dry CF, GF, or AR, but for the testing of massive metal specimens. Also, specimen dimensions of a yarn having cross sections of $0.05-2.5 \mathrm{~mm}^{2}$ are considerably smaller than metal specimens according to DIN 50125.
Various systems for specimen gripping have been established for testing devices used in the textile context [20]. They include commercially available wedge screw grips and the adhesive bonding of the specimen into sleeves by means of resin, which are subsequently screwed to the testing machine [21].

For short testing times, the mechanical inertia of moved components has a decisive effect on the results. These masses must be as small as possible as they negatively influence the transmission capacity of the measuring systems at dynamic load and thus distort measuring results. The wedge screw grips being one of the commercially available gripping devices for servo-hydraulic testing machines are not optimized for fixing technical yarns. This results in an increase in mass that must be accelerated. Aiming at a minimal construction size, the clamping of dry yarns proves to be rather difficult. Therefore, an approach involving adhesive fixation combined with an optimized construction size will be pursued. Advantages and disadvantages of adhesive bonding of the specimen will be described in the following chapters. In this regard, calculations for test speeds of up to $100 \mathrm{~m} / \mathrm{s}$ and test series using wedge screw grips in addition to four different specimen grips with adhesively bonded fixation at a speed of up to $20 \mathrm{~m} / \mathrm{s}$ were performed.

\section{Experimental}

\section{Materials}

The carbon yarn HTS 45 E23 12k 800tex (Toho Tenax Europe $\mathrm{GmbH}$, Germany) was used for measurements. To generate a specimen, the rovings were tangentially removed from the bobbin and inserted into the device to ensure a stretched and twist-free fiber orientation between clamping elements.

For adhesive bonding of the specimen, the injection resin EPIKOTE ${ }^{\circledR}$ RIMR 135 and the hardener EPIKURE ${ }^{\circledR}$ RIMH 137 were applied at a ratio of 100:30. The wedge screw grips are equipped with wavy Vulkollan clamps. The partially used metal gauze is made from stainless steel square mesh and has a division of 0.4 . Loctite 406 was used to securely fix the metal gauze to the fiber strand. All relevant characteristic values of the selected materials and construction materials are listed in Table 1.

Table 1. Material parameters

\begin{tabular}{|c|c|c|c|c|c|}
\hline Material & $\begin{array}{c}\text { Young's modulus } \\
\text { in GPa }\end{array}$ & $\begin{array}{c}\text { Density } \\
\text { in } \mathbf{g} / \mathbf{c m}^{3}\end{array}$ & $\begin{array}{c}\text { (Tensile) } \\
\text { strength in } \mathbf{M P a}\end{array}$ & $\begin{array}{c}\text { Strain to failure } \\
\left(\varepsilon_{R}\right) \text { in } \%\end{array}$ & $\begin{array}{c}\text { Minimum } \mathbf{0 . 2 \%} \text { proof } \\
\text { strength in } \mathbf{M P a}\end{array}$ \\
\hline $\begin{array}{c}\text { CF (HTS 45 E23 } \\
\text { 12k 800tex) }\end{array}$ & 240 & 1.77 & 4300 & 1.8 & - \\
\hline $\begin{array}{c}\text { Stainless steel } \\
(1.4301)\end{array}$ & 20 & 7.8 & 850 & 45 & 210 \\
\hline DirectMetal 20 & 80 & 7.6 & 400 & - & 200 \\
\hline
\end{tabular}




\section{Methods}

A comparative qualitative study of the specimen grips and clamping elements was carried out using two different tensile testing machines. One wedge screw grip and four different specimen grips were evaluated in terms of adhesive bonding of the specimen. Specimen lengths of up to $100 \mathrm{~mm}$ were tested at a speed range of up to $20 \mathrm{~m} / \mathrm{s}$. This translates to a maximum strain rate of $200 \mathrm{~s}^{-1}$.

The device Amsler HTM 5020 (Zwick, Germany) was the first machine to be tested and is a servo-hydraulic high-speed tensile testing machine [19]. By means of a hydraulic power unit, oils are pressurized up to 280 bar and utilized for the acceleration of the high-speed test cylinder when starting the machine. This cylinder grips into the piston rod having the specimen attached to it once it obtains the desired speed and breaks it. The breaking speed is thus determined by the inlet section of the piston rod. The clamping device typically comprises wedge screw grips. Force is measured by a sensor type Kistler 9071A (Kistler Instrumente $\mathrm{GmbH}$, Sindelfingen, Germany) having a measuring range of $0-400 \mathrm{kN}$. For use in this test setup, the sensor was pre-tensioned to $200 \mathrm{kN}$ and calibrated to a measuring range of $\pm 50 \mathrm{kN}$. In order to attach the specimen grips for adhesive bonding, the wedge screw grips are removed and the clamping devices are fixed to the machine. The specimen is hung into the clamp by means of a yarn grip.

The second test setup is the drop test stand [21]. It includes a drop weight, which can be released onto an anvil from a height of up to $4 \mathrm{~m}$. Force is transmitted to the specimen through the anvil and the yarn grip (Figure 3). Strain is evaluated analogously to the HTM 5020, whereas strength is recorded by a sensor-type Kistler 9311B (Kistler Instrumente $\mathrm{GmbH}$, Sindelfingen, Germany) with a measuring range of $\pm 5 \mathrm{kN}$.

All specimen grip elements presented in Table 2 were tested on both testing machines. Additionally, the wedge screw grip was tested on the HTM 5020.

The simplest type of specimen grip is presented in the form of a sleeve with an outer thread (Table 2, V1). Here, the resin system is injected through lateral holes, and the specimen is fixed to the test device via the outer thread.

The functional principle of the rotational component is similar to that of the outer thread sleeve (Table 2, V2). However, a different outer contour allows for easy handling, a defined force transmission point, and its use during high test speeds.

The laser-sintered component (Table 2, V3) enables flat clamping of the specimen, minimizing material handling during specimen preparations, and therefore reducing risk for fiber damage. Its processing includes winding and laying procedures.

The final part used in these investigations is a blind rivet nut (Table 2, V4), which allows for flat specimen clamping as well. In accordance with all previously mentioned components, the specimen is also fixed to the testing machine through a grip.

Support structures were created in order to adhesively bond the specimen to the corresponding specimen grip. Injection resin was used in all cases. For the outer thread containing sleeve, the rotational component, and the laser-sintered component, the specimen is inserted in the form of a loop into the grip, and the ends are sealed to prevent the resin from penetrating into the parallel specimen length. Subsequently, the previously degasified resin is injected via syringes, whereby the specimen is either placed in a horizontal (Figure 3b) or suspended (Figure 3a) position.

The fourth variant involves an adhesive point (Loctite 406) being added precisely to both sides, the top and bottom of the specimen, in the transition area between gripping and parallel specimen lengths. A metal gauze is then applied and pressed onto these adhesive points (Figure 4a). Hence, the Loctite penetrates into the fiber bundle and subsequently prevents the epoxy resin from moving onto the parallel specimen length due to capillary effects. In a final process step, the specimen is inserted into the yarn grip, positioned, and sealed (Figure 4b).

At least six specimens per gripping element $\mathrm{V} 1-\mathrm{V} 4$ were manufactured and tested in terms of their breaking behavior.

Table 2 Four different specimen grips to which specimens are adhesively bonded

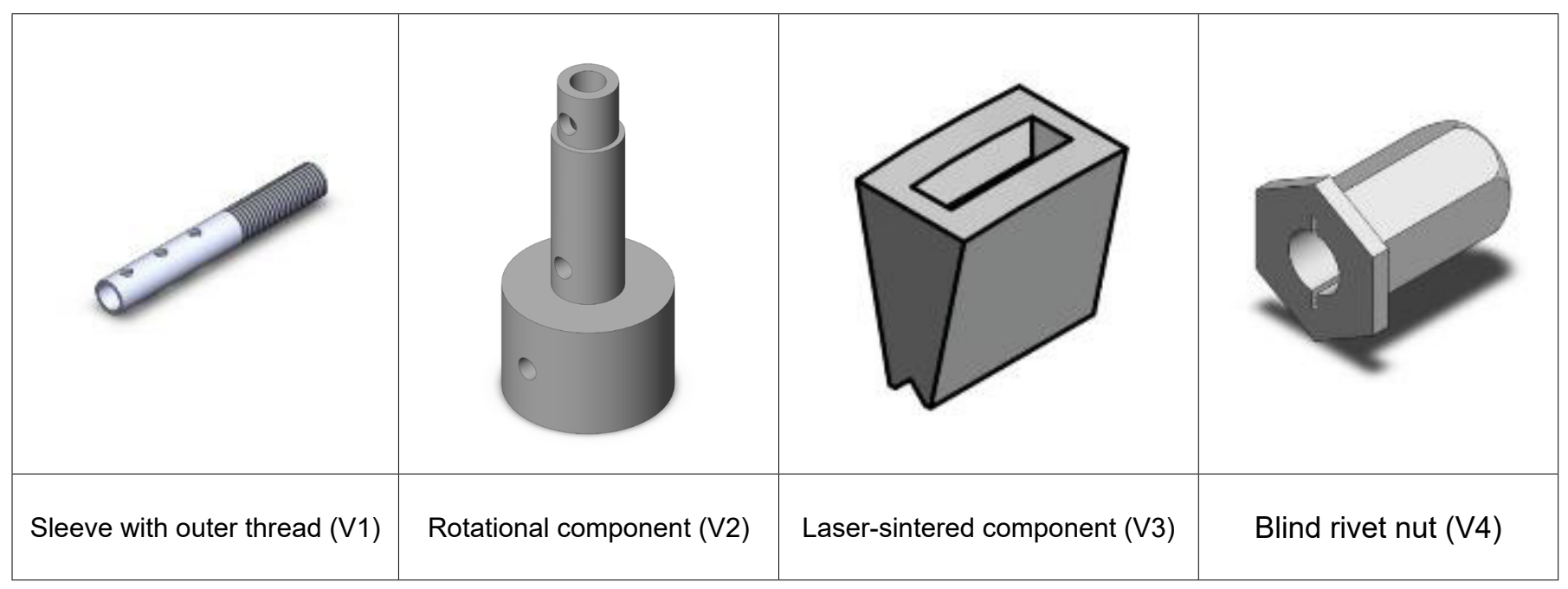



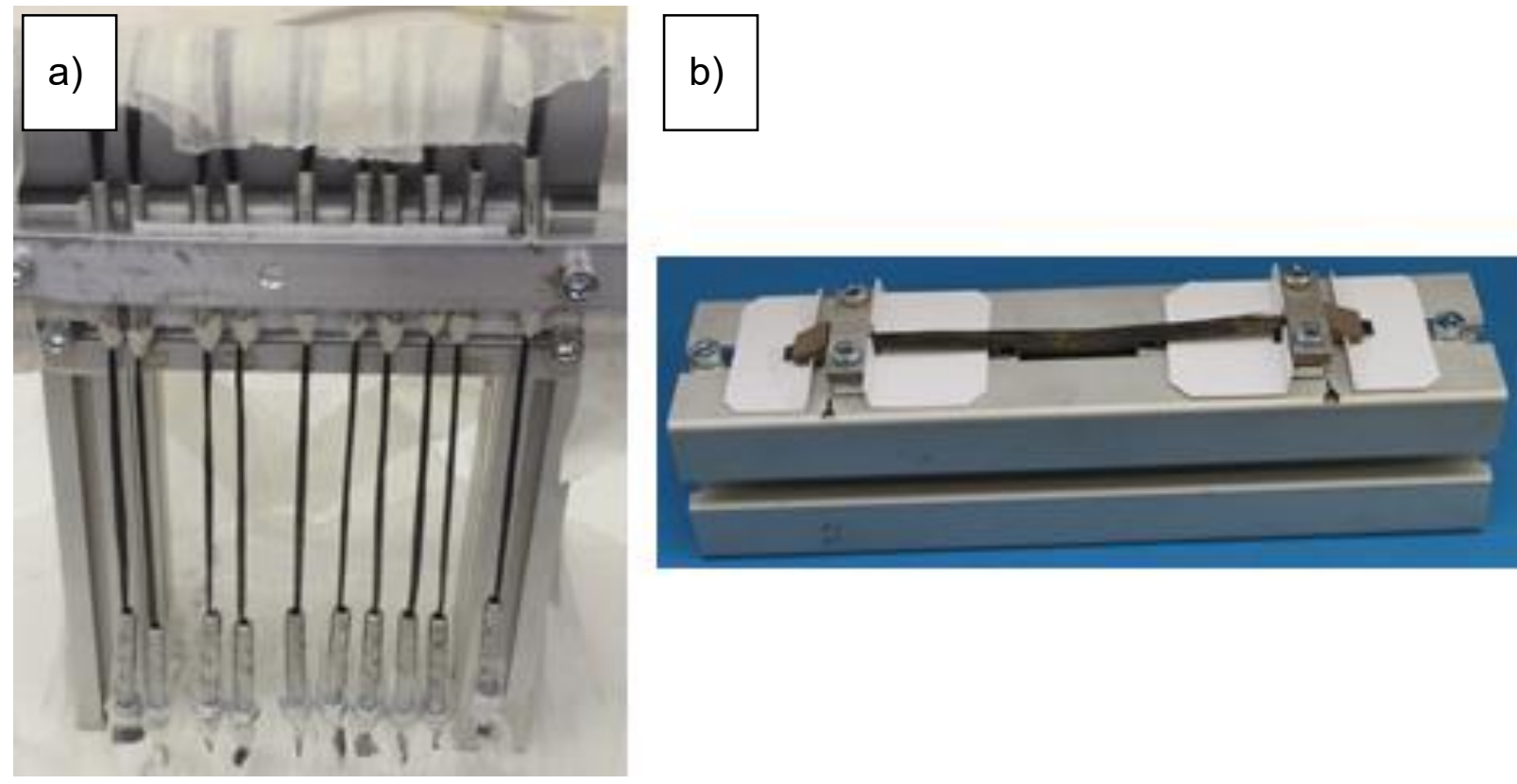

Figure 3. (a) Yarn grip for suspended clamping of V1 and V2. (b) Yarn grip for horizontal clamping of V3
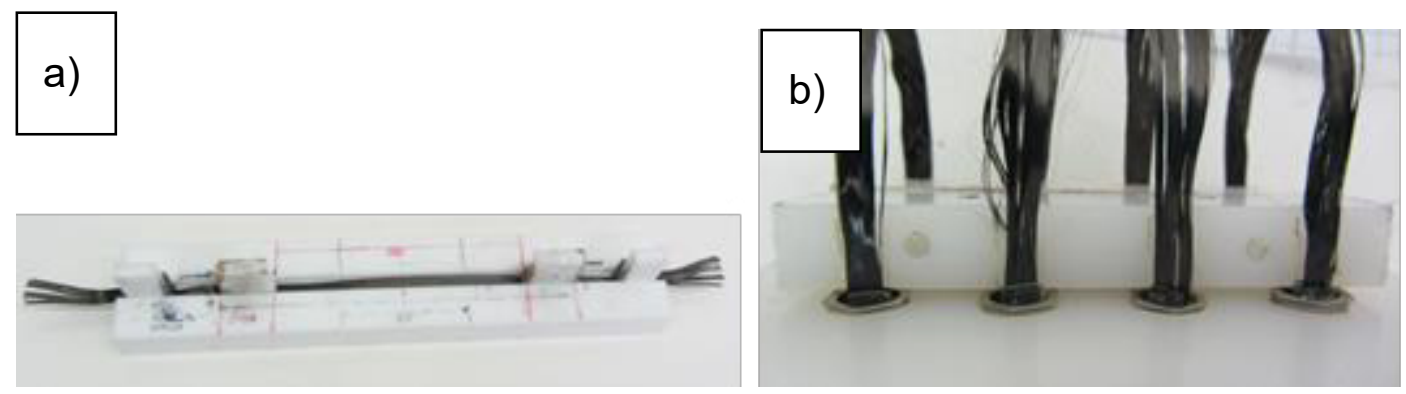

Figure 4. (a) Device for roving preparation for adhesive bonding to V4. (b) Device for resin application on rovings with epoxy

The tests were carried out according to the instruction manuals of the selected testing systems. Hence, the prepared specimens were mounted to the corresponding clamps (Figure 5) and evaluated using predefined parameters.

\section{Results and discussion}

An analytical evaluation revealed that impacts are involved in the drop tower and HTM 5020 test procedures. This is due to speed and the operation principle, according to which an accelerated machine element causes one side of the specimen and the corresponding gripping device to accelerate abruptly. Based on another assumption suggesting that the mass to be accelerated is small compared to the accelerating mass, the impact process can be described. In general, an impact comprises two phases, i.e. compression $(C)$ and restitution $(R)$ [22].

$$
p_{C}=\int_{t_{1}}^{t_{2}} F_{C}(t) d t, \quad p_{R}=\int_{t_{2}}^{t_{3}} F_{R}(t) d t
$$

Based on Newton's hypothesis of impacts, these phases can be put in relation as follows: $p_{C}=k p_{R}$ with $0 \leq k \leq 1, k=1$ in the case of a fully elastic impact, and $k=0$ in the case of plastic and inelastic impacts. Moreover, at $t_{2}$ both objects have identical speeds $u=\left(m_{1} v_{1}+m_{2} v_{2}\right)\left(m_{1}+m_{2}\right)$.

Due to the low elongation at break of the respective fiber materials, the question arises whether the desired test speed can be achieved prior to exceeding the elongation at break $\varepsilon_{B}$ of the specimen having the length $l_{0}$. For this purpose, the condition $s_{m 2}\left(t_{2}\right) \leq \varepsilon_{B} l_{0}$ must be fulfilled. The test speed can

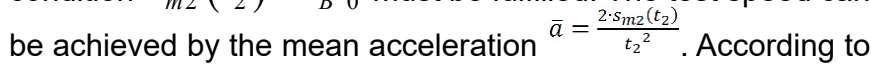
$t_{2}=\frac{\varepsilon_{B} l_{0}}{v_{1}}$ and $s_{m 2}\left(t_{2}\right)=\varepsilon_{B} l_{0}$ and if the test speed is achieved at the time of breaking, the mean acceleration can be calculated as $\bar{a} \geq \frac{2 \cdot v_{1}^{2}}{\varepsilon_{B} l_{0}}$. Based on $\sigma_{z u l} \geq \sigma=\frac{F_{G e s}}{A_{P E F E}}, F_{G e s}$ as total force, and $A_{P E F E}$ as effective surface for force transmission into the gripping device, it can be derived whether the acceleration force affecting the impact surface exceeds the material-specific yield strength.

For variant $\mathrm{V} 3$, the parameters $A_{\mathrm{PEFE}}=69 \mathrm{~mm}^{2}, m_{P E F E}=5.15 \mathrm{~g}$, $I_{0}=0.1 \mathrm{~m}$ and the CF roving parameters result in: 

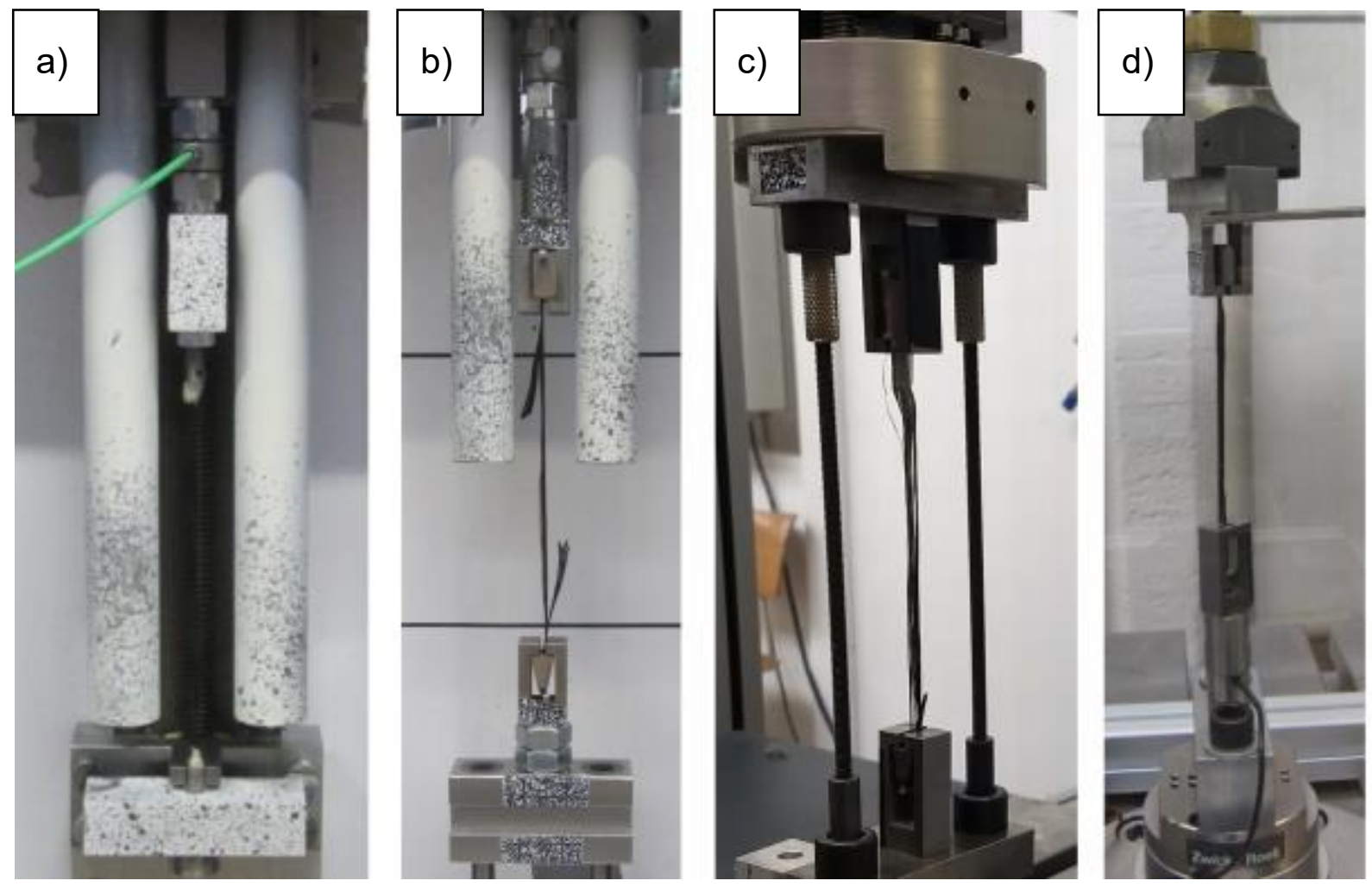

Figure 5. Yarn grips with clamps for (a) V2 on the dropping tower, (b) V3 on the dropping tower, (c) V3 on the servo-hydraulic tensile testing machine, and (d) V4 on the servo-hydraulic tensile testing machine
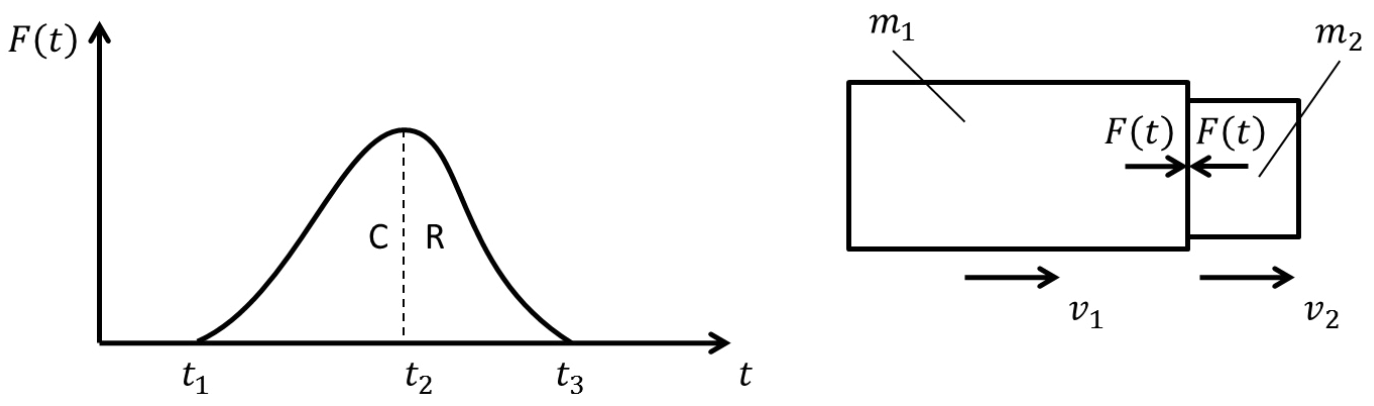

Figure 6. General force progression during impact according to the study by Grote and Feldhusen [22]

$$
A_{P E F E} \cdot \sigma_{z u l} \geq F_{G e s}=m_{P E F E} \cdot \frac{2 \cdot v_{1}^{2}}{\varepsilon_{B} l_{0}}+E_{C F} \cdot A_{C F} \cdot \varepsilon_{B}
$$

$13800 \mathrm{~N} \geq 5 \mathrm{~g} \cdot \frac{2 \cdot v_{1}{ }^{2}}{1.8 \% \cdot 0.1 \mathrm{~m}}+240000 \frac{\mathrm{N}}{\mathrm{mm}^{2}} \cdot 0.5 \mathrm{~mm}^{2} \cdot 1.8 \%$.

This inequality applies to $\mathrm{V} 3$ up to $v_{1} \cong 45 \mathrm{~m} / \mathrm{s}$. For $\mathrm{V} 4$, based on the material parameters listed in Table 1 , an impact surface of $42 \mathrm{~mm}^{2}$, and a mass of $3.7 \mathrm{~g}$ (stainless steel blind rivet nut), an elastic impact is to be expected up to a speed of $40 \mathrm{~m} / \mathrm{s}$. Once this speed is exceeded, plastic deformations are expected as a result of the impact due to the ductile material behavior of stainless steel. Hence, V3 and V4 are suitable for use at speeds above $40 \mathrm{~m} / \mathrm{s}$. These insights were included in the development process of grips $\mathrm{V} 2$ to $\mathrm{V} 4$.

\section{Analysis and evaluation of yarn grips V1-V4}

First, the grips $\mathrm{V} 1-\mathrm{V} 4$ were fitted with CF rovings and tested on the drop tower. During the preparation of $\mathrm{V} 1$ and $\mathrm{V} 2$, rovings exceeding 660 tex, which includes the HTS 45 E23 12k used for this research, must be reshaped into a round crosssectional geometry to facilitate subsequent drilling. Originally, their shape is flat when wound onto a bobbin. This presents a major source of errors to the following test procedure as single filaments can be damaged and the stretched position of filaments may be flawed. This issue was solved by use of a device that holds the roving in a stretched position while causing minimal deformation prior to adhesive bonding; this approach was employed for V4.

According to DIN EN ISO 2062, breakage resulting from gripping is not relevant in terms of specimen material behavior and must be excluded from test series. Several specimens of all yarn grip types broke due to gripping, which can be attributed to insufficient integration of the specimen into the grip. Figure 7 shows images of the prepared specimens for $\mathrm{V} 1$ prior to testing. Figure $7 b$ and $c$ shows the results of specimen grips with and without breakage. Figure $7 d$ provides an example of the results obtained with blind rivet nuts. 
a)

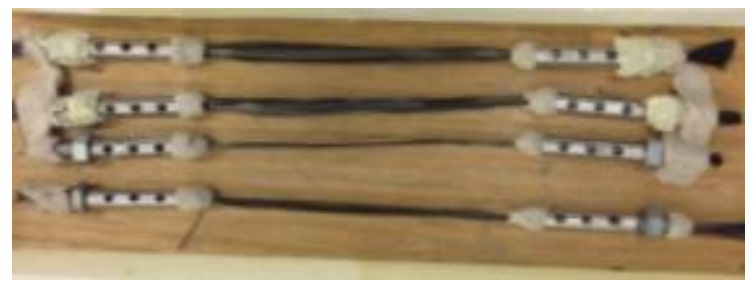

c)

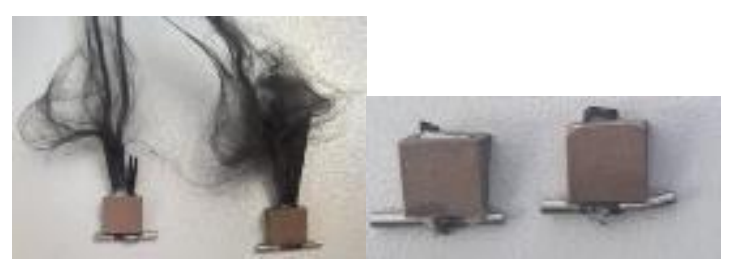

b)

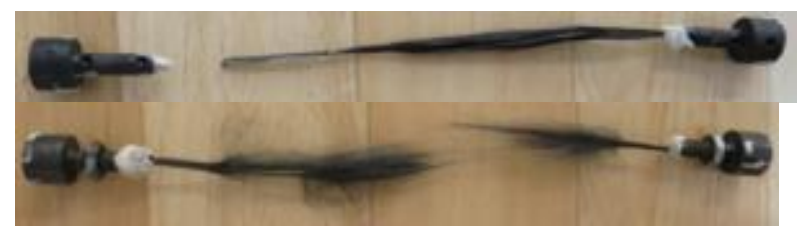

d)

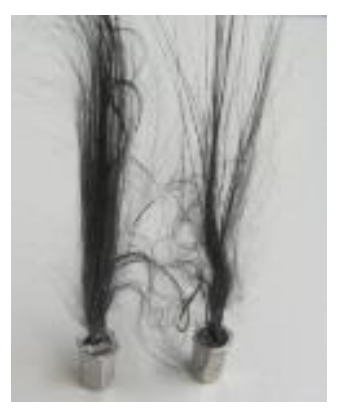

Figure 7. (a) Prepared sleeve with outer thread V1. (b) Rotational component V2 after testing with gripping breakage (left) and without gripping breakage (right). (c) Laser-sintered component V3 after testing with gripping breakage (left) and without gripping breakage (right). (d) Stainless steel blind rivet nut $\mathrm{V} 4$ after testing; no gripping breakage

These investigations suggest that the outer thread sleeve (V1) and the rotational component (V2) are suitable for dynamic tensile testing. However, results may be distorted as specimens are compressed during the preparation process. Tests performed with the laser-sintered component (V3) revealed that increased shear forces occur due to the guiding of specimens and lead to a clamping breakage rate of $50 \%$. Thus, although this construction type has an optimized external geometry, it was not considered further.

The blind rivet nut (V4) provided reproducible results. $62 \%$ of the tested specimens exhibited breakage that occurred in conformity with standards in the middle section of the parallel specimen length. The internal contour of this element was identified as the cause for this behavior as it ensures a stretched and undistorted embedding of the roving as well as a form-fit connection with the epoxy resin.

Wedge screw grips provide specific advantages in terms of gripping flexibility and do not require laborious preparation efforts. However, acting forces can neither be modified directly nor sufficiently. Undefined varying shear forces either lead to pull-out as gripping forces cannot properly fixate the specimens or breakage due to major discontinuities in the transition area between clamp and parallel length.

The clamping of the specimen poses an enormous challenge, and improper fixation is the most common reason for invalid tests. Investigations carried out within this research project revealed that suspended or horizontal specimen positions during preparation tend to cause poorer results. The resin used for injection must have a low viscosity and so it can flow through the needle, which simultaneously leads to the resin diffusing into the parallel specimen length due to capillary effects. Therefore, in some cases, the yarn is completely infiltrated and no longer applicable for testing. Moreover, a specimen cannot be moved once it was infiltrated. Hence, it must be positioned precisely and with a high degree of repeat accuracy. In conclusion, V4 has proven to be suitable for this preparation method and was therefore selected as the basis for further investigation.

\section{CONCLUSIONS}

In the case of technical yarns with low elongations at break, their requirement-adapted clamping for high-speed tensile testing is a challenging task. The low elongation at break of the fibers to be tested leads to extremely short test durations and involves fast acceleration. Additionally, CF rovings are very sensitive to shear force, which must be taken into consideration. With regard to the previously described test scenarios, investigations focused on gripping effects at singleaxis tensile load in the dynamic range.

The duration of high-speed tensile tests is extremely short. Hence, large forces apply during acceleration phases. Based on calculations, the elastic yarn grips of V3 and V4 are suitable for test speeds up to approximately $40 \mathrm{~m} / \mathrm{s}$. Above this speed, a purely elastic case can no longer be obtained since deformations increase or the yarn grip dimension would have to be reduced. Neglecting the fact that $\mathrm{V} 4$ is not reusable, it can be applied in the plastic range.

Based on the performed practical examinations, four different yarn grip types to which specimens are adhesively bonded and a wedge screw grip were tested. In addition, three methods 
for the adhesive bonding of specimens were analyzed. The laser-sintered component and a modified blind rivet nut proved to be particularly suitable for high-speed tensile testing. With regard to adhesive bonding, a method involving superglue being applied to the specimen to prevent it from complete infiltration was successfully developed and implemented. Hence, a constantly high level of quality can be guaranteed during specimen preparation.

All yarn grips were positioned firmly on the used testing machines, independent of the type of energy input. It was shown that these devices are suitable for test speeds up to $20 \mathrm{~m} / \mathrm{s}$. Furthermore, gripping breakage can be reduced by the newly developed adhesive bonding method. With regard to further developments, the blind rivet nut is considered the most promising approach as it enables mass reductions as well as the gentle guiding and gripping of fiber bundles. Due to its form-fit connection and minimized size, reproducible results can be generated even at higher test speeds.

\section{ACKNOWLEDGEMENTS}

The DFG project $\mathrm{CH} 174 / 41-1$ was supported by the Deutsche Forschungsgemeinschaft (DFG). The financial support is gratefully acknowledged.

\section{D $G \begin{aligned} & \text { Deutsche } \\ & \text { Forschungsgemeinschaft }\end{aligned}$}

\section{References}

[1] Bleck, W., Frehn, A., Larour, P., Steinbeck, G. (2004). Untersuchungen zur Ermittlung der Dehnratenabhängigkeit von modernen Karosseriestählen. Materialwissenschaft und Werkstofftechnik, 35(8), S. 505-513.

[2] Gizik, D., et al. Heavy tow carbon fibers for aerospace applications. In: ADDITCStuttgart November 30 December 1, 2017.

[3] Schuler, H., Mayrhofer, C., Thoma, K. (2006). Spall experiments for the measurement of the tensile strength and fracture energy of concrete at high strain rates. International Journal of Impact Engineering, 32(10), S. 1635-1650.

[4] Lindner, M., Vanselow, K., Gelbrich, S., Kroll, L. (2018). Fiberreinforced polymers based rebar and stirrup reinforcing concrete structures. Journal of Materials Science and Engineering A, 8(2).

[5] Chokri, C. (Ed.) (2016). Textile materials for lightweight constructions (1 ed.). Springer (Berlin, Heidelberg).

[6] Al-Mosawe, A., Al-Mahaidi, R., Zhao, X. -L. (2017). Engineering properties of CFRP laminate under high strain rates. Composite Structures, 180, S. 9-15.
[7] Kwon, J. et al. (2016). Evaluation of the effect of the strain rate on the tensile properties of carbon-epoxy composite laminates. Journal of Composite Materials, 51(22), S. 3197-3210.

[8] Kwon, J. B., Huh, H., Ahn, C. N. An improved technique for reducing the load ringing phenomenon in tensile tests at high strain rates, S. 253-257.

[9] Naresh, K., Shankara, K., Rao, B. S., Velmurugan, R. (2016). Effect of high strain rate on glass/carbon/hybrid fiber reinforced epoxy laminated composites. Composites Part B: Engineering, 100, S. 125-135.

[10] Pariti, V. N. P. M. (2017). Mechanical behavior of carbon and glass fiber reinforced composite materials under varying loading rates. Michigan, University of Michigan-Dearborn, Mechanical Engineering (Masterthesis, Michigan).

[11] Zhang, X., Hao, H., Shib, Y., Cui, J., Zhang, X. (2016). Static and dynamic material properties of CFRP/epoxy laminates. Construction and Building Materials, 114, S. 638-649.

[12] Zhu, B., et al. (2018). Dynamic Measurement of FoamSized Yarn Properties from Yarn Sequence Images. AUTEX RESEARCH JOURNAL, 18. (3.).

[13] Bilisik, K., et al. (2017). Development of multistitched three-dimensional (3d) nanocomposite and evaluation of its mechanical and impact properties. AUTEX Research Journal, 17(3), S. 238-249.

[14] Ashir, M., et al. (2018). Influence of defined amount of voids on the mechanical properties of carbon fiber-reinforced plastics. Polymer Composites, 15(2), S. 170.

[15] Ashir, M., et al. (2018). Development and mechanical properties of adaptive fiber-reinforced plastics. Journal of Industrial Textiles, S. 152808371875752.

[16] Wang, Y., et al. Statistical analysis on high strain rate tensile strength of T700 carbon fiber. In: Proceedings of the ASME International Mechanical Engineering Congress and Exposition 2007, Seattle, Washington, USA, November 11-15, 2007. - ISBN 0-7918-4304-1, S. 557-560.

[17] Zhou, Y., et al. (2010). Tensile behavior of carbon fiber bundles at different strain rates. Materials Letters, 64(3), S. 246-248.

[18] Field, J. E., et al. (2004). Review of experimental techniques for high rate deformation and shock studies. International Journal of Impact Engineering, 30(7), S. 725-775.

[19] Zwick/Roell: Product Information - High-Speed Testing Machine Amsler HTM 5020, 8020. http://www.zwickusa. com/no_cache/en/products/dynamic-and-fatigue-testingmachines/servo-hydraulic-testing-machines/htm-highspeed-testing-machines-from-25-to-160-kn.html?tx z7treedependingdownloads_pi1\%5Bfile\%5D $=512$.

[20] Zwick/Roell: The specimen under control - Specimen grips and test tools. http://www.zwickusa.com/no_cache/ en/products/specimen-grips-and-test-fixtures.html?tx z7treedependingdownloads_pi1\%5Bfile $\% 5 D=713$.

[21] Younes, A., et al. (2012). Stress-strain behavior of carbon filament yarns under high strain rates. Textile Research Journal, 82(7), S. 685-699.

[22] Grote, K. -H., Feldhusen, J. (Ed.) (2014). Dubbel (24 ed.). Springer (Berlin, Heidelberg). 